\title{
NEUROLOGIC OUTCOME AFTER ASCENDING AORTA-AORTIC ARCH OPERATIONS: EFFECT OF BRAIN PROTECTION TECHNIQUE IN HIGH-RISK PATIENTS
}

Christian Hagl, MD

M. Arisan Ergin, $\mathrm{MD}, \mathrm{PhD}^{\mathrm{a}}$

Jan D. Galla, MD, $\mathrm{PhD}^{\mathrm{a}}$

Steven L. Lansman, MD, $\mathrm{PhD}^{\mathrm{a}}$

Jock N. McCullough, MD, $\mathrm{PhD}^{\mathrm{a}}$

David Spielvogel, $\mathrm{MD}^{\mathrm{a}}$

Pierre Sfeir, MD

Carol A. Bodian, DrPH ${ }^{b}$

Randall B. Griepp, MD
Objective: We sought to assess the optimal strategy for avoiding neurologic injury after aortic operations requiring hypothermic circulatory arrest.

Methods: All 717 patients who survived ascending aorta-aortic arch operations through a median sternotomy since 1986 were examined for factors influencing stroke. Temporary neurologic dysfunction was assessed in all patients who survived the operation without stroke since 1993. Multivariate analyses were carried out to determine independent risk factors for neurologic injury.

Results: Independent risk factors for stroke were as follows: age greater than 60 years $(P<.001$; odds ratio, 4.5$)$; emergency operation $(P=.02$; odds ratio, 2.2); new preoperative neurologic symptoms $(P=.05$; odds ratio, 2.9$)$; presence of clot or atheroma $(P<.001$; odds ratio, 4.4$)$; mitral valve replacement or other concomitant procedures $(P=.055$; odds ratio, $=3.7)$; and total cerebral protection time, defined as the sum of hypothermic circulatory arrest and any retrograde or antegrade cerebral perfusion $(P=.001$; odds ratio, 1.02/min). In 453 patients surviving operations without stroke after 1993 , independent risk factors for temporary neurologic dysfunction included age $(P<.001$; odds ratio, $1.06 / y)$, dissection $(P=.001$; odds ratio, 2.2$)$, need for coronary artery bypass grafting $(P=.006$; odds ratio, 2.1$)$ or other procedures $(P=.023$; odds ratio, 3.4$)$, and total cerebral protection time ( $P$ $<.001$; odds ratio, $1.02 / \mathrm{min})$. When all patients with total cerebral protection times between 40 and 80 minutes were examined, the method of cerebral protection did not influence the occurrence of stroke, but antegrade cerebral perfusion resulted in a significant reduction in incidence on temporary neurologic dysfunction $(P=.05$; odds ratio, 0.3$)$.

Conclusions: The occurrence of stroke is principally determined by patientand disease-related factors, but use of antegrade cerebral perfusion can significantly reduce the occurrence of temporary neurologic dysfunction. ( $\mathrm{J}$ Thorac Cardiovasc Surg 2001;121:1107-21)
D espite the improved results of more extensive operations on the thoracic aorta since the introduction of hypothermic circulatory arrest (HCA), these complex procedures are still associated with a relatively high

From the Departments of Cardiothoracic Surgery a and Biomathematics, ${ }^{\mathrm{b}}$ Mount Sinai School of Medicine/New York University, New York, NY.

Read at the Twenty-sixth Annual Meeting of The Western Thoracic Surgical Association, The Big Island, Hawaii, June 21-24, 2000.

Copyright (C) 2001 by The American Association for Thoracic Surgery

$0022-5223 / 2001 \$ 35.00+0 \quad \mathbf{1 2 / 6 / 1 1 3 1 7 9}$

doi: $10.1067 / \mathrm{mtc} .2001 .113179$ mortality and a disturbing incidence of neurologic complications.

The early clinical experience with HCA indicated that there are 2 distinct pathophysiologic mechanisms of cerebral damage after operations on the thoracic aorta. ${ }^{1}$ Most permanent serious neurologic complications are the result of strokes, which are usually attributable to embolic phenomena. In addition, many patients, especially those whose operations require longer intervals of interruption of normal antegrade cerebral perfusion (ACP), have more subtle but diffuse injury, resulting in the clinical symptom complex that we have termed temporary neurologic dysfunction (TND). ${ }^{1}$ This second type of injury correlates with the duration of HCA and 
almost certainly results from inadequate cerebral protection. ${ }^{1}$ Despite the apparent reversibility of many symptoms of TND, it has recently been shown that this early manifestation of diffuse cerebral damage is associated with long-term deficits in cognitive function. ${ }^{2-4}$

The relatively high rate of adverse neurologic outcomes has prompted a search for alternative or supplemental methods of brain protection during prolonged intervals of circulatory arrest required for complex aortic operations. These methods include ACP and retrograde cerebral perfusion (RCP). We have used these methods in conjunction with HCA. ACP was used mainly to limit the duration of circulatory arrest, and RCP was used mainly to flush out debris in an attempt to prevent embolic strokes in patients at risk for particulate embolization. In addition, use of alternative cannulation sites other than the femoral artery was implemented to eliminate the diseased descending aorta as a source for retrograde embolization to the brain during cardiopulmonary bypass.

The purpose of this report is to analyze neurologic outcome (stroke and TND) at a single institution in all patients who underwent repair of the thoracic portion of the aorta through a median sternotomy with the use of HCA. We also examined the effect of different neuroprotective perfusion techniques on the incidence of brain injury in high-risk patients requiring complex operations.

\section{Patients and methods}

Patient characteristics. A total of 717 consecutive patients who survived thoracic aortic operations with HCA through a median sternotomy at Mount Sinai Hospital from August 1986 to November 1999 were reviewed. Median age was 64 years (range, 8-89 years), and 58\% of the patients were older than 60 years at the time of the operation. Almost two thirds of the patients were male $(66 \%)$. The majority of patients, 458 (64\%), were operated on electively, 100 (14\%) were operated on urgently (between 16 and 72 hours after admission), and 159 (22\%) were operated on on an emergency basis (within 16 hours after admission). One hundred seventy-five (24\%) patients had undergone previous cardiac or aortic operations through a sternotomy or lateral thoracotomy.

The underlying cause was dissection in $322(45 \%)$ patients and atherosclerosis in $125(17 \%)$ patients. Of the remaining 270 patients, $154(22 \%)$ were classified as having degenerative aneurysms (featuring cystic medial necrosis), 54 (7.5\%) as having annuloaortic ectasia, and $31(4.3 \%)$ as having the features of Marfan syndrome. Sixty-two (8.6\%) had miscellaneous lesions of mycotic or other cause.

A history of hypertension was the most common general preoperative risk factor $(56 \%)$, followed by a history of smoking (47\%) and diabetes mellitus (7.4\%). Sixty-six $(9.2 \%)$ patients had a previous neurologic history (carotid artery disease, transient ischemic attack, prolonged reversible ischemic neurologic deficit, or frank stroke).

Surgical technique. Definition of the extent of replacement was simplified for analysis into 2 major groups according to the segment of the aorta that dominated the repair, as described previously by Ergin and colleagues. ${ }^{1}$ A proximal repair (replacement of the ascending aorta or the aortic root, including portions of the proximal aortic arch, where the distal anastomosis was accomplished with a single suture line) was done in $569(79 \%)$ patients; a modified Bentall operation was done in $66 \%$ of all proximal repairs. In 145 (20\%) patients the total arch was replaced, with reanastomosis of the brachiocephalic vessels with an elephant trunk procedure in $25(3.5 \%)$ patients.

For assessment of clot or atheroma, a computed tomographic or magnetic resonance imaging examination, as well as transesophageal echocardiography, were performed before the surgical procedure in all patients. In cases in which potentially embolic material was found, alternative cannulation sites other than the femoral artery (right axillary or left subclavian artery) were considered. These alternative sites for arterial cannulation were used routinely in the last 2 years. Hemodynamic monitoring included radial arterial pressure lines, as well as a pulmonary artery catheter. Since 1993, an additional catheter was placed to sample jugular venous oxygen saturation to estimate the cerebral metabolic rate before induction of HCA. Transesophageal echocardiography was routinely used to assess cardiac performance, intracardiac air, flow conditions, and special aortic pathologic conditions.

All patients were operated on through a median sternotomy incision and, unless contraindications were present, cannulated within the mediastinum by means of a low-resistance cannula in the aorta and a 2-staged venous cannula in the right atrium. In patients in whom RCP was considered, a Y connection was added to the arterial part of the circuit. After cardiopulmonary bypass had been established, cooling was instituted to reach core temperatures of $10^{\circ} \mathrm{C}$ to $13^{\circ} \mathrm{C}$.

In all cases of proximal repair, an open anastomosis was performed. In total arch reconstructions, cerebral vessels were excised on an island of native aorta, and an anastomosis of the arch cap with a 16- to 20-mm Hemashield graft (Boston Scientific Corporation, Natick, Mass) was performed, as shown in Fig 1. All patients received $2 \mathrm{~g}$ of methylprednisolone before institution of HCA and an additional $1.5 \mathrm{~g}$ of methylprednisolone during the next 48 hours if HCA time exceeded 30 minutes. Rewarming was instituted gradually and discontinued at a core temperature of $32^{\circ} \mathrm{C}$ to $33^{\circ} \mathrm{C}$.

Neurologic evaluation. All patients who died intraoperatively or during the first 24 hours after the operation without an opportunity for adequate evaluation of their neurologic status were excluded from the study. This seemed appropriate because even patients with a major neurologic insult during the operation rarely die within such a short time. Patients were considered to have had strokes if they exhibited the onset of focal deficits postoperatively or were found to have a focal lesion confirmed by means of computed tomographic scanning or magnetic resonance imaging of the brain. Patients with neurologic deficits that resolved before discharge were classified 
as having had transient strokes, distinguishing them from those with permanent strokes, who had persisting deficits at the time of discharge from the hospital. The total incidence of stroke (transient plus permanent) was used for maximal power in univariate and multivariate analysis.

For evaluation of TND (defined as postoperative confusion, agitation, delirium, prolonged obtundation, or transient parkinsonism), all patients who underwent their operation before 1994 were excluded because of the institution of a more scrupulous evaluation of this kind of neurologic injury thereafter. Patients who died intraoperatively or whose postoperative neurologic status could not adequately be assessed before death, as well as those who underwent strokes, were excluded from the analysis for TND.

Cerebral protection techniques. Selection of the perfusion method used for cerebral protection was not random but was related to the surgeon's preference. There were 588 patients with only HCA, 43 in whom HCA was used in conjunction with RCP, and 86 in whom selective ACP was used (Table I). During an interval of several years in which enthusiasm for RCP was relatively great, it was usually chosen for patients in whom, as a result of the presence of visible clot or atheroma in the aorta, the risk of embolization was judged to be high. In contrast, ACP was disproportionately frequently chosen for patients with more extensive operations, in whom prolonged interruption of the cerebral circulation was anticipated.

Comparative demographic variables show no significant differences between the groups with different cerebral protection methods. However, emergencies were more frequently seen in the HCA only group $(P=.001)$ because of the preponderance of acute type A dissections in this group, commonly requiring a proximal repair. Dissection was the most common cause among patients with HCA only $(P=$ $.001)$, and aortic atherosclerosis was the most common cause among patients with ACP. There were no patients with only proximal repairs in the ACP group, whereas the operation involved the proximal aorta in $69 \%$ of the HCA only group $(P=.001)$, who therefore had a much higher proportion of aortic valve replacements or repairs $(P=.001)$. As anticipated by the rationale for its use, clot or atheroma was more prevalent in the RCP group $(P=.002)$.

HCA was carried out as previously described in detail. Core cooling with alpha-stat blood gas management was used to achieve an esophageal temperature of $10^{\circ} \mathrm{C}$ to $13^{\circ} \mathrm{C}$, and the head was packed in ice during the interval of circulatory arrest. In the later years of the study, especially when longer intervals of HCA were anticipated, cooling was continued until the jugular venous saturation exceeded $95 \%$, indicating maximal suppression of cerebral metabolism. Care was taken to cool long enough to prevent a significant upward drift of temperature during the interval of circulatory arrest.

Continuous RCP as a method of cerebral protection during arrest of antegrade circulation or as a brief retrograde wash in an attempt to flush out particular debris was used in only 43 patients. RCP flow was initiated through the superior vena cava cannula and was regulated to achieve a pressure of 15 to $20 \mathrm{~mm} \mathrm{Hg}$ in the superior vena cava.
Table I. TCPT for all 717 patients who survived ascending aorta-aortic arch operations through a median sternotomy incision

\begin{tabular}{lccc}
\hline $\begin{array}{l}\text { TCPT } \\
(\text { min })\end{array}$ & $\begin{array}{c}\text { HCA only } \\
(n=588)\end{array}$ & $\begin{array}{c}R C P \\
(n=43)\end{array}$ & $\begin{array}{c}A C P \\
(n=86)\end{array}$ \\
\hline$<20$ & 152 & 3 & 0 \\
$20-30$ & 237 & 9 & 1 \\
$30-40$ & 116 & 13 & 1 \\
$40-60$ & 71 & 14 & 26 \\
$60-80$ & 12 & 4 & 29 \\
$80-100$ & 0 & 0 & 12 \\
$>100$ & 0 & 0 & 17
\end{tabular}

Total brain protection time is equal to HCA time for patients in whom this was the only method of cerebral protection or HCA time plus the interval of RCP or ACP.

In cases of ACP, the arterial line was inserted into a Hemashield graft containing the island of arch vessels, and perfusion was started after careful aspiration of the head vessels (Fig 1). The temperature of the perfusate was maintained between $10^{\circ} \mathrm{C}$ and $12^{\circ} \mathrm{C}$, and the flow was adjusted to maintain an arterial pressure of 50 to $60 \mathrm{~mm} \mathrm{Hg}$. The graft containing the island of arch vessels was then incorporated into the aortic arch repair during a second short interval of HCA.

To compare the different techniques of cerebral protection, we defined a period that reflects the time required to accomplish the technical maneuvers in the operation before resumption of normal antegrade perfusion of the whole body and refer to it as the total cerebral protection time (TCPT). In the HCA group TCPT corresponds to the interval of circulatory arrest, in the RCP group TCPT is equal to the sum of HCA and RCP times, and in the ACP group TCPT is the sum of the duration of HCA and of selective ACP. Table I shows the TCPT for all 717 patients. Analysis of the specific effect of perfusion techniques on neurologic outcome was restricted to patients with TCPT from 40 to 80 minutes' duration because a 40-minute interval, both experimentally and clinically, appears to be at the upper limit of protection afforded by hypothermia alone. This TCPT interval in this series also included adequate numbers of patients using each of the techniques, allowing a more meaningful comparison.

Statistical methods. Comparisons of putative risk factors between groups defined by use of different cerebral protection techniques, as well as univariate analyses of risk factors for stroke or for TND, were conducted by using $\chi^{2}$ tests for categoric variables; continuous variables were grouped and examined for continuous trends or threshold values by means of $\chi^{2}$ tests. Each set of univariate analyses of neurologic outcome (for stroke or TND) was followed by stepwise logistic regression to identify independent risk factors. In analyses that included perfusion techniques, their independent influence was tested by adding to the model after other relevant factors were identified.

The analyses for stroke and TND were conducted separately. Risk factors for stroke were examined in all patients who survived the operation long enough to allow neurologic evaluation, and risk factors for TND were assessed in 


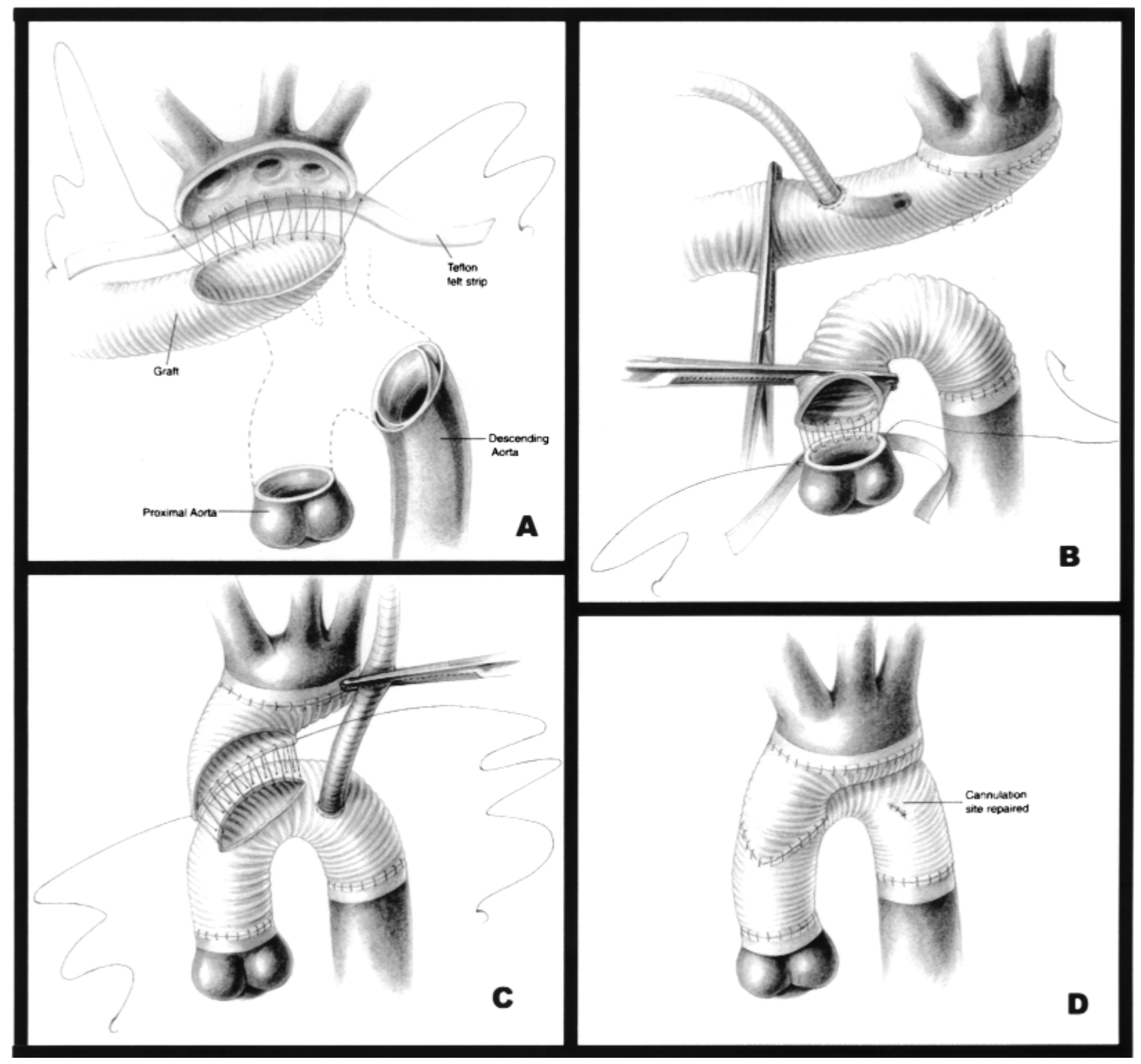

Fig 1. The simplified technique for selective ACP used at Mount Sinai, showing incorporation of the cerebral vessel graft into the arch repair. A, The cap of cerebral vessels, dissected from the native arch, is sutured to an appropriately shaped 14- to 16-mm Hemashield graft by using a running 3-0 polypropylene suture reinforced with Teflon felt. B, An arterial inflow cannula has been inserted, the proximal end of the graft has been clamped, and selective ACP has been initiated with blood at $15^{\circ} \mathrm{C}$ to $20^{\circ} \mathrm{C}$ to achieve pressure of 50 to $60 \mathrm{~mm} \mathrm{Hg}$ in either radial artery (flow rate, $800-1200 \mathrm{~mL} / \mathrm{min}$ ). A second Hemashield graft is shown after the reinforced distal anastomosis has been completed and the proximal anastomosis is being constructed. $\mathbf{C}$, The arch reconstruction is being completed by means of a graft-to-graft anastomosis of the proximal-distal arch and cerebral vessel grafts during a brief (5-10 minute) interval of HCA. D, The completed repair. This technique can be combined with axillary artery cannulation to minimize risk of embolization.

patients after 1993 who survived the operation without strokes, as explained earlier. These analyses could not address the influence of cerebral protection technique on neurologic outcome because the choice of cerebral protection technique was confounded with TCPT, as seen in Table I. All 3 cerebral protection techniques were adequately rep- resented only for TCPTs between 40 and 80 minutes. Therefore, the analysis of risk factors for stroke and for TND was repeated as outlined above in the subgroup of patients with a TCPT of 40 to 80 minutes, including testing for the independent influence of cerebral protection technique on neurologic outcome. 


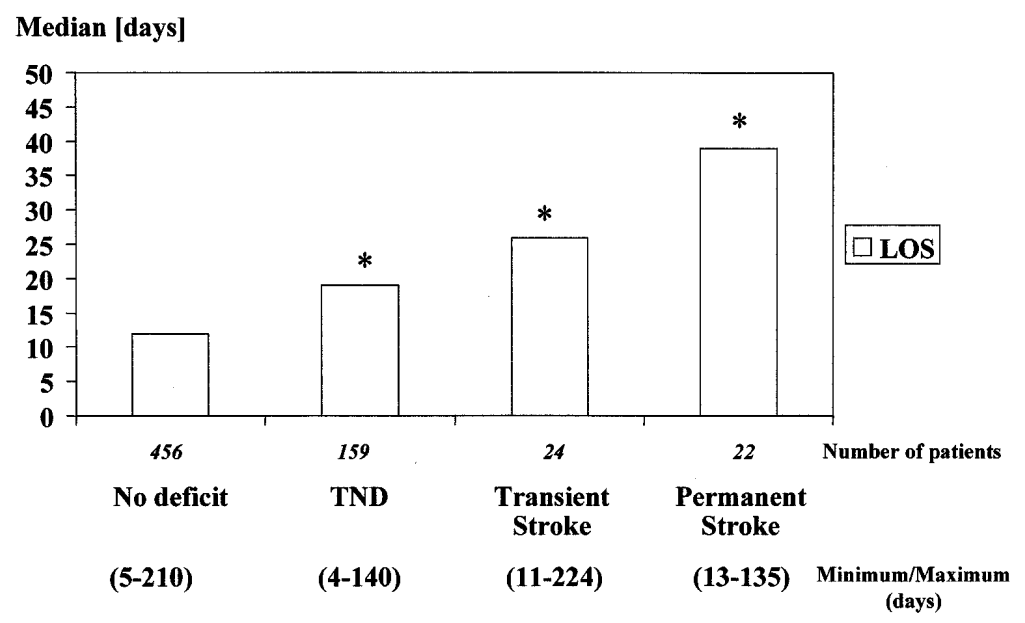

Fig 2. Effect of neurologic injury on median length of hospitalization in all patients who survived until discharge from the hospital. $L O S$, Length of stay; $T N D$, temporary neurologic dysfunction. $* P<.001$ versus no deficit.

To provide greater statistical power in identifying risk factors, we examined transient and permanent strokes together. The question of whether this approach is justified (ie, whether factors associated with the risk of permanent stroke are the same as those associated with transient stroke) was addressed in 2 ways. Among the patients who had a stroke, $\chi^{2}$ tests were used to compare the proportions of patients with permanent and transient strokes separately for each putative risk factor. In addition, the data were entered in an ordinal stepwise logistic model with the outcomes of no stroke, transient stroke, and permanent stroke and tested for the homogeneity of 2 sets of odds ratios (ORs): (1) permanent or transient stroke versus no stroke and (2) permanent stroke versus transient or no stroke.

All data were analyzed with SAS software (SAS Institute, Inc, Cary, NC) on a VAX computer (Compaq Computer Corporation, Houston, Tex).

\section{Results}

Of all patients who underwent ascending aorta-aortic arch operations through a median sternotomy during the interval under study, 17 of the 734 patients died in the operating room or shortly thereafter before adequate assessment of neurologic function was possible. Fiftysix of the operative survivors died before discharge from the hospital, resulting in an overall mortality of $10 \%$. The adverse effect of neurologic injury on recovery after aortic operations is readily apparent from mortality statistics: $41 \%$ of patients with permanent strokes died before hospital discharge. Use of RCP was also associated with a slightly but not significantly higher mortality than other methods of cerebral protection.

Of the patients who survived, as shown in Fig 2, patients with no neurologic complications had a median length of stay significantly shorter than those with
TND. Patients with either transient or permanent stroke had considerable further increases in median length of hospital stay than did patients without neurologic injury.

Stroke. Among all 717 patients in the study, a transient stroke occurred in $24(3.3 \%)$ patients, and 37 $(5.7 \%)$ patients had a permanent stroke. There were no historical differences in the prevalence of stroke over the interval under scrutiny from 1986 to $1999(P=.7)$.

Univariate analysis for stroke (either transient or permanent) revealed a number of preoperative and intraoperative risk factors (Table II). Preoperative predictors of stroke included age greater than 60 years $(P=.001)$, emergency operation $(P=.006)$, atherosclerosis as the underlying cause $(P=.001)$, presence of coronary artery disease $(P=.02)$, and occurrence of new preoperative neurologic symptoms $(P=.01)$. A history of smoking $(P=.05)$ or of previous neurologic symptoms $(P=0.11)$ was marginally significant as a risk factor for stroke. Intraoperative variables significant as risk factors for stroke included total arch repair $(P=.006)$, contained hematoma $(P=.002)$, presence of visible clot or atheroma $(P=.001)$, and TCPT $(P=.001)$. Among all the factors tested, only total arch repair, the presence of contained hematoma (a sign of imminent rupture), and TCPT showed a significant differential effect on transient versus permanent strokes, all predisposing toward more permanent strokes. The incidence of transient and permanent strokes in relation to each factor is also shown in Table II.

No comparison of cerebral protection techniques in relation to stroke incidence was undertaken in the group as a whole because of the inextricable intertwining of different cerebral protection techniques and 
Table II. Univariate and multivariate analysis for stroke in all 717 patients

\begin{tabular}{|c|c|c|c|c|c|c|}
\hline & & & & & ny stroke & \\
\hline & $n$ & $\begin{array}{l}\text { Transient } \\
\text { stroke (\%) }\end{array}$ & $\begin{array}{l}\text { Permanent } \\
\text { stroke (\%) }\end{array}$ & Univariate & Multivariate & OR \\
\hline Preoperative factors & & & & & & \\
\hline Age & & & & $P=.001$ & $P=.006$ & 4.4 \\
\hline Age $\leq 60$ y & 302 & 1.3 & 1.0 & & & \\
\hline Age $>60 y$ & 415 & 4.8 & 8.2 & & & \\
\hline Ever smoked & & & & $P=.05$ & & \\
\hline No & 380 & 2.4 & 4.2 & & & \\
\hline Yes & 337 & 4.5 & 6.2 & & & \\
\hline Coronary artery dis & & & & $P=.02$ & & \\
\hline No & 575 & 2.8 & 4.5 & & & \\
\hline Yes & 142 & 5.6 & 7.8 & & & \\
\hline Urgency & & & & $P=.006$ & $P=.02$ & 2.2 \\
\hline No emergency & 159 & 3.1 & 3.9 & & & \\
\hline Emergency & 558 & 4.4 & 9.4 & & & \\
\hline Cause & & & & $P=.001$ & & \\
\hline Atherosclerosis & 125 & 6.4 & 11.2 & & & \\
\hline Dissection & 322 & 3.7 & 6.2 & & & \\
\hline Others & 270 & 1.5 & 1.1 & & & \\
\hline Previous neurologi & & & & $P=.12$ & & \\
\hline No & 651 & 3.2 & 4.8 & & & \\
\hline Yes & 66 & 4.6 & 9.1 & & & \\
\hline New preoperative $n$ & & & & & & \\
\hline symptoms & & & & $P=.012$ & $P=.05$ & 2.9 \\
\hline No & 689 & 3.2 & 4.8 & & & \\
\hline Yes & 28 & 7.1 & 14.3 & & & \\
\hline Marfan syndrome & & & & $P=.08$ & & \\
\hline No & 686 & 3.5 & 5.4 & & & \\
\hline Yes & 31 & 0 & 0 & & & \\
\hline Intraoperative factors & & & & & & \\
\hline Extent of operation & & & & $P=.006$ & & \\
\hline Proximal & 572 & 3.5 & 3.5 & & & \\
\hline Arch & 145 & 2.8 & 11.7 & & & \\
\hline $\begin{array}{l}\text { Mitral valve replac } \\
\text { concomitant }\end{array}$ & & & & $P=.48$ & $P=.055$ & 3.7 \\
\hline No & 691 & 3.2 & 5.2 & & & \\
\hline Yes & 26 & 7.7 & 3.9 & & & \\
\hline Contained hematon & & & & $P=.002$ & & \\
\hline No & 622 & 3.4 & 3.9 & & & \\
\hline Yes & 95 & 3.2 & 13.7 & & & \\
\hline Clot or atheroma & & & & $P=.001$ & $P<.001$ & 4.4 \\
\hline No & 601 & 2.5 & 2.7 & & & \\
\hline Yes & 116 & 7.8 & 18.1 & & & \\
\hline TCPT & & & & $P=.001$ & $P=.001$ & $1.02 / \mathrm{min}$ \\
\hline
\end{tabular}

TCPT. Patients undergoing ACP and RCP had significantly longer TCPTs than patients undergoing HCA. In addition, almost all patients undergoing ACP had total arch replacement, which carries a high risk of stroke, whereas the proportion of arch replacements when either RCP or only HCA were used was smaller. The groups with different cerebral protection techniques also varied in preoperative risk factors for stroke. The distribution of emergency and elective operations dif- fered; there were more patients with visible clot or atheroma in the group with RCP, and more patients with atherosclerotic aneurysms were in the ACP group.

In the multivariate analysis of the group as a whole, independent risk factors for stroke were as follows: age greater than 60 years $(P=.0006$; OR, 4.4; Fig 3$)$; emergency operation $(P=.023$; OR, 2.2); the presence of clot or atheroma $(P<.001 ; \mathrm{OR}, 4.2)$; and TCPT $(P=$ .001; OR, 1.02/min; Fig 4). A steady increase in the 
Table III. Characteristics of patients with TCPT between 40 and 80 minutes

\begin{tabular}{|c|c|c|c|c|c|}
\hline & $\begin{array}{c}\text { All patients } \\
(n=156)\end{array}$ & $\begin{array}{c}H C A \\
(n=83)\end{array}$ & $\begin{array}{c}H C A+R C P \\
\quad(n=18)\end{array}$ & $\begin{array}{c}H C A+A C P \\
\quad(n=55)\end{array}$ & $\mathrm{P}$ value \\
\hline \multicolumn{6}{|l|}{ Preoperative factors } \\
\hline Age & & & & & .126 \\
\hline Age $\leq 60 \mathrm{y}$ & $45(28.8 \%)$ & $21(25.3 \%)$ & $3(16.7 \%)$ & $21(38.2 \%)$ & \\
\hline Age $>60 y$ & $111(71.2 \%)$ & $62(74.7 \%)$ & $15(83.3 \%)$ & $34(61.8 \%)$ & \\
\hline History of hypertension & & & & & .091 \\
\hline No & $47(30.1 \%)$ & $31(37.3 \%)$ & $5(27.8 \%)$ & $11(20.0 \%)$ & \\
\hline Yes & $109(69.9 \%)$ & $52(62.7 \%)$ & $13(72.2 \%)$ & $44(80.0 \%)$ & \\
\hline Coronary artery disease & & & & & .079 \\
\hline No & $123(78.8 \%)$ & $71(85.5 \%)$ & $12(66.7 \%)$ & $40(72.7 \%)$ & \\
\hline Yes & $33(21.1 \%)$ & $12(14.5 \%)$ & $6(33.3 \%)$ & $15(27.3 \%)$ & \\
\hline Urgency & & & & & .005 \\
\hline Emergency & $41(26.3 \%)$ & $32(38.5 \%)$ & $2(11.1 \%)$ & $7(12.7 \%)$ & \\
\hline No emergency & $115(63.7 \%)$ & $51(61.5 \%)$ & $16(88.9 \%)$ & $48(87.3 \%)$ & \\
\hline Cause & & & & & .001 \\
\hline Atherosclerosis & $48(30.8 \%)$ & $17(20.5 \%)$ & $6(33.3 \%)$ & $25(45.5 \%)$ & \\
\hline Dissection & $94(60.3 \%)$ & $59(71.1 \%)$ & $7(38.9 \%)$ & $28(50.9 \%)$ & \\
\hline Others & $14(8.9 \%)$ & $7(7.4 \%)$ & $5(27.8 \%)$ & $2(3.6 \%)$ & \\
\hline New preoperative neurologic symptoms & & & & & .064 \\
\hline No & $150(96.2 \%)$ & $77(92.8 \%)$ & $18(100 \%)$ & $55(100 \%)$ & \\
\hline Yes & $6(3.8 \%)$ & $6(7.2 \%)$ & $0(0 \%)$ & $0(0 \%)$ & \\
\hline \multicolumn{6}{|l|}{ Intraoperative factors } \\
\hline Extent of operation & & & & & .001 \\
\hline Proximal & $66(42.3 \%)$ & $57(68.7 \%)$ & $9(50.0 \%)$ & $0(0 \%)$ & \\
\hline Arch & $90(57.7 \%)$ & $26(31.3 \%)$ & $9(50.0 \%)$ & $55(100 \%)$ & \\
\hline CABG & & & & & .060 \\
\hline No & $131(84.0 \%)$ & $67(80.7 \%)$ & $13(72.2 \%)$ & $51(92.7 \%)$ & \\
\hline Yes & $25(16.0 \%)$ & $16(19.3 \%)$ & $5(27.8 \%)$ & $4(7.3 \%)$ & \\
\hline Contained hematoma & & & & & .037 \\
\hline No & $128(82.1 \%)$ & $63(75.9 \%)$ & $14(77.8 \%)$ & $51(92.7 \%)$ & \\
\hline Yes & $28(17.9 \%)$ & $20(24.1 \%)$ & $4(22.2 \%)$ & $4(7.3 \%)$ & \\
\hline Clot or atheroma & & & & & .002 \\
\hline No & $101(64.7 \%)$ & $57(68.7 \%)$ & $5(27.8 \%)$ & $39(70.9 \%)$ & \\
\hline Yes & $55(35.3 \%)$ & $26(31.3 \%)$ & $13(72.2 \%)$ & $16(29.1 \%)$ & \\
\hline
\end{tabular}

$C A B G$, Coronary artery bypass grafting.

risk of stroke with increasing TCPT was evident in the HCA group and the ACP group but not in the RCP group, most of whose TCPTs were between 20 and 60 minutes. The presence of new preoperative neurologic symptoms, frequently found in patients with acute dissections, was of borderline significance $(P=.06$; OR, 2.8). All factors except TCPT were homogeneous for transient and permanent stroke: longer TCPT was associated with greater risk of permanent stroke.

When only the 156 patients with prolonged TCPT (40-80 minutes) were included in a multivariate analysis, age greater than 60 years was the only significant risk factor for stroke $(P=.037 ; \mathrm{OR}, 8.9)$. There was no influence of perfusion technique on the incidence of stroke in this group with prolonged TCPT. Some caution should be exercised in interpreting the failure of cerebral protection techniques to influence the rate of stroke. The apparent inability of these techniques to prevent strokes might be influenced by the fact that the patients with RCP and ACP were at a higher risk for strokes because of other predisposing factors, such as a higher incidence of coronary artery disease, of atherosclerotic origin of the aneurysm, and of more extensive operation (Table III). Patients with RCP also had a higher incidence of clot or atheroma and higher rates of concomitant coronary artery bypass operations. On the other hand, patients with HCA were more likely to have undergone operations on an emergency basis and to have had dissections and new neurologic symptoms, factors associated with increased risk of stroke.

TND. For all patients operated on after 1993 ( $\mathrm{n}=$ 453), the TND rate was $30 \%$. As was true for stroke, there was no influence of year of operation on the risk of TND $(P=.993)$ during this period. 


\section{Stroke [\%]}

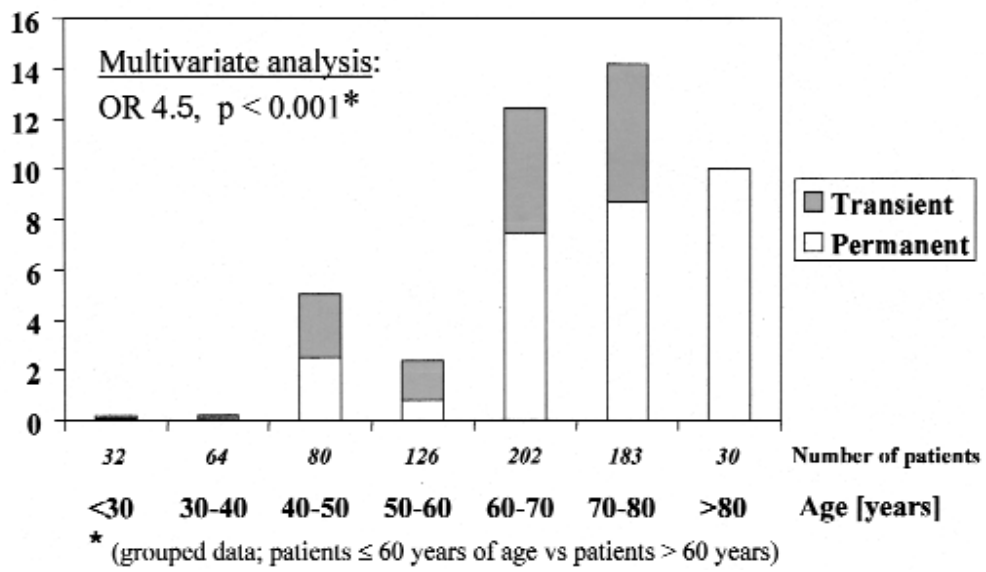

Fig 3. Effect of increasing age on incidence of stroke, transient or permanent, in all patients $(n=717)$.

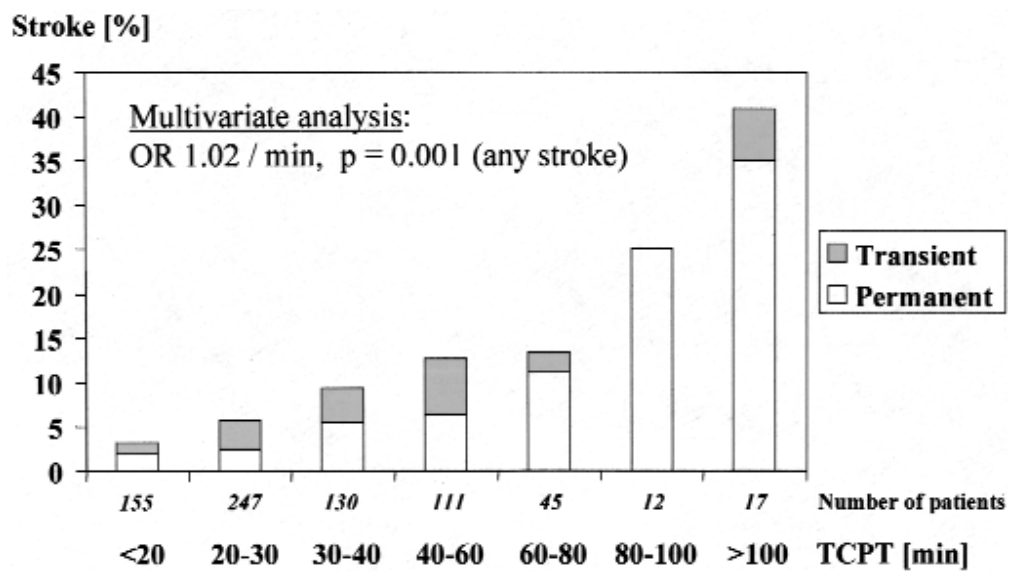

Fig 4. Effect of increasing duration of cerebral protection (TCPT) on incidence of stroke, either transient or permanent, in all patients $(n=717)$. In the HCA group TCPT corresponds to the interval of HCA, in the RCP group TCPT is equal to the sum of HCA and RCP times, and in the ACP group TCPT is the sum of the duration of HCA and selective ACP.

Univariate analysis demonstrated a number of preoperative variables as significant risk factors for TND (Table IV): female sex $(P=.007)$; age $(P=.001$, Fig 5); the presence of coronary artery disease $(P=.038)$; dissection as the underlying cause of aortic disease $(P=.001)$; emergency operation $(P=.004)$; and a history of previous neurologic events $(P=.021)$. Intraoperative factors that reached significance for TND in univariate analysis (Table IV) included the following: total arch operation $(P=.001)$; concomitant coronary artery bypass grafting procedure $(P=.001)$; blood in the pericardium $(P=.027)$; contained hematoma $(P=.015)$; appearance of clot or atheroma $(P=.001)$; and TCPT $(P=.001$, Fig 6).
Multivariate analysis revealed the following independent risk factors for TND: age as a continuous variable $(P=.0001 ; \mathrm{OR}, 1.06 / \mathrm{y})$; dissection $(P=.001 ; \mathrm{OR}, 2.2)$; need for coronary artery bypass grafting $(P=.006$; OR, $2.1)$ or other procedures $(P=.023 ; \mathrm{OR}, 3.4)$; and TCPT $(P=.001 ; \mathrm{OR}, 1.02 / \mathrm{min}$; Figs 4 and 5$)$.

In the group with TCPTs from 40 to 80 minutes' duration $(\mathrm{n}=91)$, age $(P=.002$; OR, $1.06 / \mathrm{y})$, atherosclerosis $(P=.009 ;$ OR, 14.9), and dissection $(P=$ .028; OR, 8.1) were all significant independent risk factors for TND (Table V). The use of ACP significantly decreased the risk for TND in this group $(P=.048$; OR, 0.33). To isolate the apparent influence of ACP in reducing the incidence of TND from the effects of 
Table IV. Univariate and multivariate analysis for TND for all patients after $1993(n=453)$

\begin{tabular}{|c|c|c|c|c|c|}
\hline & \multicolumn{2}{|c|}{$T N D$} & \multirow[b]{2}{*}{ Univariate } & \multirow[b]{2}{*}{ Multivariate } & \multirow[b]{2}{*}{$O R$} \\
\hline & $n$ & $\%$ & & & \\
\hline \multicolumn{6}{|l|}{ Preoperative factors } \\
\hline Sex & & & $P=.007$ & & \\
\hline Female & 152 & 38.2 & & & \\
\hline Male & 301 & 25.9 & & & \\
\hline Age & & & $P=.001$ & & \\
\hline Age $\leq 60$ y & 192 & 16.7 & & $P<.001$ & $1.06 / y$ \\
\hline Age $>60 y$ & 261 & 39.9 & & & \\
\hline History of hypertension & & & $P=.110$ & & \\
\hline No & 182 & 25.8 & & & \\
\hline Yes & 271 & 32.8 & & & \\
\hline Coronary artery disease & & & $P=.038$ & & \\
\hline No & 339 & 27.4 & & & \\
\hline Yes & 114 & 37.7 & & & \\
\hline Urgency & & & $P=.004$ & $P=.004$ & 2.0 \\
\hline Emergency & 92 & 42.4 & & & \\
\hline No emergency & 361 & 26.9 & & & \\
\hline Cause & & & $P=.001$ & & \\
\hline Atherosclerosis & 69 & 42.0 & & & \\
\hline Dissection & 179 & 40.8 & & $P=.001$ & 2.2 vs all \\
\hline Others & 205 & 16.6 & & & \\
\hline Previous neurologic history & & & $P=.021$ & & \\
\hline No & 414 & 28.5 & & & \\
\hline Yes & 39 & 46.2 & & & \\
\hline Marfan syndrome & & & $P=.058$ & & \\
\hline No & 434 & 30.9 & & & \\
\hline Yes & 19 & 10.5 & & & \\
\hline Aortic valve disease & & & $P=.007$ & & \\
\hline None & 324 & 34.3 & & & \\
\hline Prosthetic & 57 & 21.1 & & & \\
\hline Bicuspid & 72 & 18.1 & & & \\
\hline \multicolumn{6}{|l|}{ Intraoperative factors } \\
\hline Extent of operation & & & $P=.001$ & & \\
\hline Proximal & 369 & 26.6 & & & \\
\hline Arch & 84 & 45.2 & & & \\
\hline CABG & & & $P=.001$ & $P=.007$ & 2.0 \\
\hline No & 352 & 25.6 & & & \\
\hline Yes & 101 & 45.5 & & & \\
\hline Mitral valve replacement or other concomitant procedures & & & $P=.092$ & $P=.02$ & 3.3 \\
\hline No & 434 & 29.3 & & & \\
\hline Yes & 19 & 47.4 & & & \\
\hline Blood in pericardium & & & $P=.027$ & & \\
\hline No & 424 & 28.8 & & & \\
\hline Yes & 29 & 48.3 & & & \\
\hline Contained hematoma & & & $P=.015$ & & \\
\hline No & 407 & 28.3 & & & \\
\hline Yes & 46 & 45.7 & & & \\
\hline Clot or atheroma & & & $P=.001$ & $P=.09$ & 1.8 \\
\hline No & 408 & 27.0 & & & \\
\hline Yes & 45 & 57.8 & & & \\
\hline Cardiopulmonary bypass time & & & $P=.039$ & & \\
\hline TCPT & & & $P=.001$ & $P<.001$ & $1.02 / \mathrm{min}$ \\
\hline
\end{tabular}

$C A B G$, Coronary artery bypass grafting.

other covariables, we conducted a stringent stepwise analysis for these confounding factors. The addition of the factors to the model did not change the observed influence of ACP in reducing the incidence of TND. $(P$ values for these factors ranged from .29 to .99 in the model, with ACP maintaining its predictive value.) Although patients undergoing RCP appeared to have had a slightly higher incidence of TND than those with HCA alone, the difference did not reach statistical significance. 


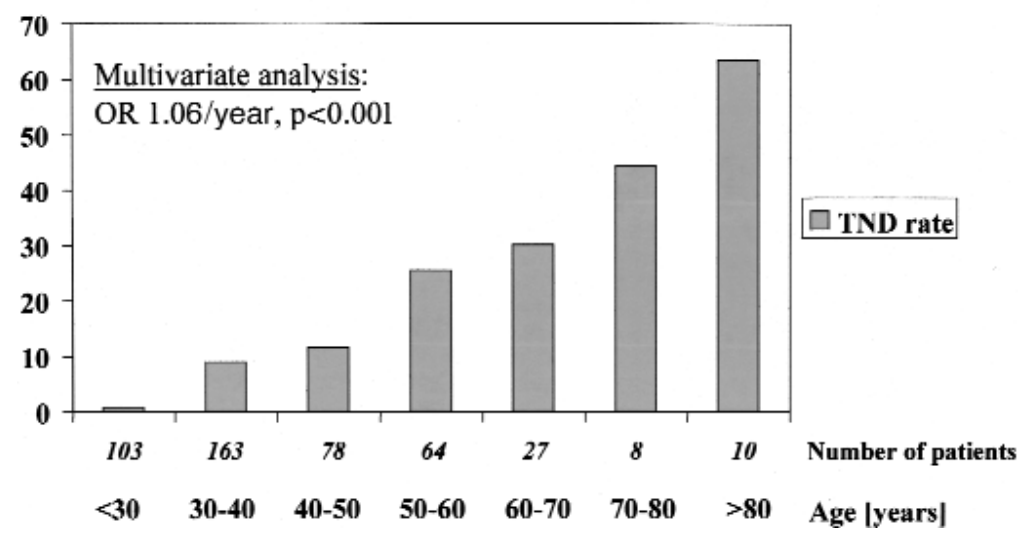

Fig 5. Effect of increasing age on incidence of TND, as defined in the text, in all patients after 1993 who survived operation without stroke $(\mathrm{n}=453)$.

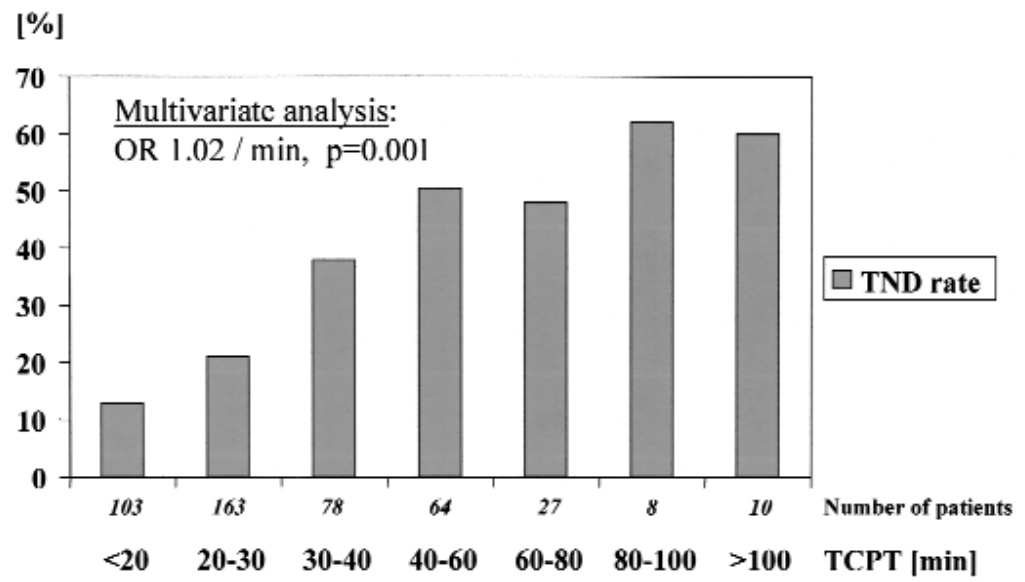

Fig 6. Effect of increasing duration of cerebral protection (TCPT) on incidence of TND, as defined in the text, in all patients after 1993 who survived operation without stroke $(n=453)$. In the HCA group TCPT corresponds to the interval of HCA, in the RCP group TCPT is equal to the sum of HCA and RCP times, and in the ACP group TCPT is the sum of the duration of HCA and of selective ACP.

Although there was no effect of TCPT on the incidence of TND in the 40- to 80-minute subgroup, the data from the larger group (Fig 7) did show a significant effect of TCPT on TND. Because TCPT exceeding 80 minutes involves predominantly the use of $\mathrm{ACP}$, this indicates that even ACP is not quite safe for prolonged periods.

\section{Discussion}

The best approach to protecting the brain during operations on the thoracic portion of the aorta, in which the arterial blood supply has to be interrupted tem- porarily, is still a matter of controversy. ${ }^{5}$ Our approach has been to try to maximize protection during HCA by cooling thoroughly and by limiting the duration of HCA. During the interval under study, we used RCP mainly with the aim of reducing embolization but relied principally on ACP as an adjunct to HCA when longer durations of HCA were anticipated.

Although experience with RCP has now lasted almost 10 years, ${ }^{6}$ there is still controversy about whether RCP has a neuroprotective effect above and beyond that provided by HCA. Although some uptake of oxygen during retrograde flow clearly occurs, most 
Table V. Univariate and multivariate analysis for TND (TCPT, 40-80 minutes), excluding all patients with stroke $(n=91)$

\begin{tabular}{|c|c|c|c|c|c|}
\hline & \multicolumn{2}{|c|}{$T N D$} & \multirow[b]{2}{*}{ Univariate } & \multirow[b]{2}{*}{ Multivariate } & \multirow[b]{2}{*}{$O R$} \\
\hline & $n$ & $\%$ & & & \\
\hline \multicolumn{6}{|l|}{ Preoperative factors } \\
\hline Sex & & & $P=.06$ & & \\
\hline Female & 38 & 57.9 & & & \\
\hline Male & 53 & 37.7 & & & \\
\hline Age & & & $P=.001$ & $P=.002$ & $1.06 / y$ \\
\hline Age $\leq 60$ y & 31 & 19.4 & & & \\
\hline Age $>60 y$ & 60 & 60.0 & & & \\
\hline Cause & & & $P=.05$ & & \\
\hline Atheromatosis & 25 & 64.0 & & $P=.009$ & 14.9 vs all others \\
\hline Dissection & 56 & 42.9 & & $P=.03$ & $8.1 \mathrm{vs}$ all others \\
\hline Others & 10 & 20.0 & & & \\
\hline Reoperation & & & $P=.040$ & & \\
\hline No & 64 & 53.1 & & & \\
\hline Yes & 27 & 29.6 & & & \\
\hline Marfan syndrome & & & $P=.103$ & & \\
\hline No & 88 & 47.7 & & & \\
\hline Yes & 3 & 0 & & & \\
\hline \multicolumn{6}{|l|}{ Intraoperative factors } \\
\hline CABG & & & $P=.02$ & & \\
\hline No & 76 & 40.8 & & & \\
\hline Yes & 15 & 73.3 & & & \\
\hline Clot or atheroma & & & $P=.03$ & & \\
\hline No & 72 & 40.3 & & & \\
\hline Yes & 19 & 68.4 & & & \\
\hline Blood in pericardium & & & $P=.09$ & & \\
\hline No & 83 & 43.4 & & & \\
\hline Yes & 8 & 75.0 & & & \\
\hline \multicolumn{6}{|l|}{ Perfusion type } \\
\hline HCA only & 34 & 52.9 & & & \\
\hline $\mathrm{RCP}$ & 13 & 69.2 & & $P=.34$ & 2.2 vs HCA only \\
\hline $\mathrm{ACP}$ & 44 & 34.1 & & $P=.05$ & 0.3 vs HCA only \\
\hline
\end{tabular}

of the efforts to document significant improvement in cerebral metabolic function as a result of nutritive flow during RCP have failed. Furthermore, experimental studies have shown that significant shunting of blood away from the brain occurs during RCP through venovenous anastomoses. ${ }^{7}$ Nevertheless, there may be a positive influence of RCP on cooling, which helps to protect the brain, especially in those patients in whom systemic cooling is not as thorough and prolonged as it should be. We continue to believe that a major benefit of RCP in the studies of others-usually with a historical control group and with duration of RCP so short that good results would be anticipated with use of HCA alone-can be explained largely by the improved cooling brought about by continuous bathing of the brain with cold blood during RCP. This effective cooling provided by RCP may make a difference, especially if the initial cooling interval is short and the head is not packed in ice. Several experimental studies reinforce this view. ${ }^{8}$

Others have shown a remarkable positive effect of RCP: a dramatic reduction of the stroke rate and a beneficial effect on both stroke rate and mortality. ${ }^{9-11}$ In the current and in earlier ${ }^{12}$ studies, however, we have been unable to demonstrate any benefit of RCP in our patients. Experimental data from our laboratory suggest that RCP, especially at high pressures, although successful in removing some emboli, may aggravate cerebral injury. ${ }^{13}$ Although the greater prevalence of patients with clot or atheromata in the RCP group in the current study may partially explain why our results show no decrease in the prevalence of stroke with RCP, it nevertheless is also possible that flushing the arterial vessels by using RCP may not be effective in preventing stroke. Hospital mortality was higher among patients in whom RCP was used, and the TND rate in 


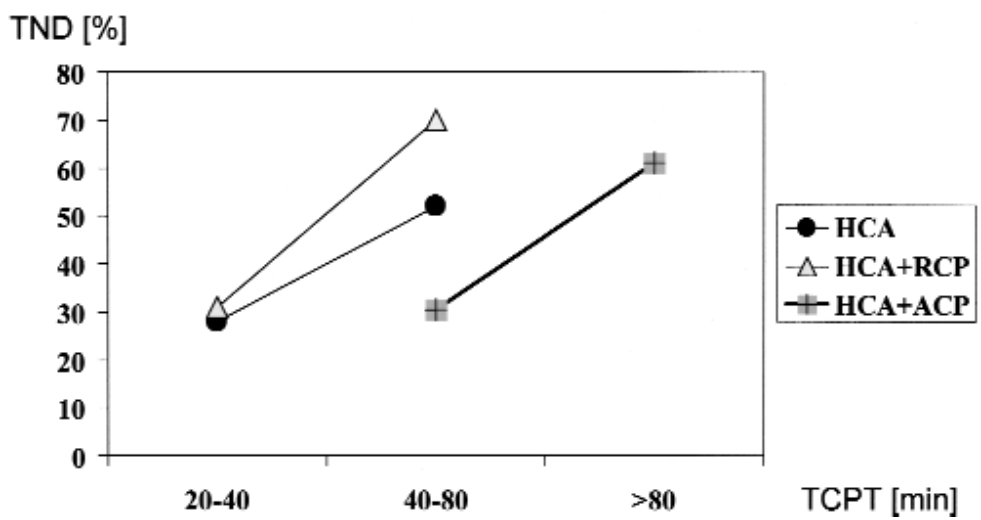

Fig 7. Effect of increasing duration of cerebral protection on incidence of TND, as defined in the text, fractionated according to the cerebral protection method in all patients who survived operation without stroke since 1993 $(n=453)$. In the HCA group TCPT corresponds to the interval of HCA, in the RCP group TCPT is equal to the sum of HCA and RCP times, and in the ACP group it is the sum of the duration of HCA and of selective ACP. Although differences in patient selection require that comparisons between the groups undergoing different modes of cerebral protection be undertaken with caution, it is interesting to note that the incidence of TND with increasing TCPT appears to increase more sharply with RCP than with HCA alone, and that the levels of TND with ACP are comparatively low despite longer TCPT.

the group with TCPTs between 40 and 80 minutes was significantly higher with RCP than with ACP. Furthermore, RCP resulted in no reduction of TND compared with HCA alone, reinforcing the notion that RCP probably has no nutritive value for brain tissue. The induction of cerebral edema, documented in our animal studies of RCP, ${ }^{13}$ cannot easily be demonstrated in the clinical situation but may be another reason for our repeated observation of delayed neurologic recovery postoperatively in patients treated with RCP.

In contrast to the lack of benefit seen with adjunctive $\mathrm{RCP}, \mathrm{ACP}$ is associated with better cerebral recovery after prolonged HCA in our study. ACP often requires complicated cannulation techniques, and accidental embolization of atheromatous debris during manipulation of the arch vessels is a widely known and justly feared complication. Several modifications of selective antegrade perfusion have been introduced, including variations in cannulation sites and use of lower perfusion temperatures, ${ }^{14-16}$ which have resulted in recent favorable outcomes in the hands of several investigators. ${ }^{17}$ With the use of an island of arch vessels, as shown in Fig 1, ACP can be initiated through the graft during an initial interval of HCA and maintained until the aortic repair is completed (by means of anastomosis of the principal aortic graft with the island containing the arch vessels during a second interval of HCA). This method has gradually become the technique of choice in our institution for aortic arch operations when more extensive operations are planned and may have contributed to the observed reduction of neurologic morbidity when ACP was used.

Our data show that the TND rate in the patients with prolonged TCPTs between 1994 and 1996 was 53\% compared with $39 \%$ after 1996, which was when we began to use ACP more frequently in patients with more extensive operations. The significantly lower rate of TND after 40 to 80 minutes of TCPT with ACP when compared with RCP or HCA alone in this study is convincing evidence of the superior cerebral protection provided by ACP when prolonged operations are undertaken. Antegrade administration of oxygenated cold blood delivers energy for brain tissue, can remove toxic metabolites, and improves cooling of the brain, thereby prolonging the safe duration of HCA.

However, our results do not imply that ACP gives us the luxury of unlimited time to complete an aortic repair. Our data suggest that there may be a critical point, perhaps a TCPT exceeding 80 minutes, beyond which cerebral protection, even with ACP, is suboptimal. Such a time limit has to be taken into consideration, especially when contemplating use of multivessel aortic arch grafts, which require a separate anastomosis for each cerebral vessel. Although these techniques may result in a more complete resection of the diseased aorta and avoid reconstruction in the atheromatous arch near the origin of the cerebral vessels, the decrease in the risk of embolization inherent in this method may come at the price of exceeding the duration of safe ACP. 
In contrast to its positive effect on TND, ACP has not been helpful in preventing stokes. The results of the multivariate analysis in all 717 patients for stroke showed that almost all the important factors predisposing to stroke are patient or disease related. Age greater than 60 years and intraoperatively observed clots or atheromata were the strongest predictors for stroke. Emergency operation and occurrence of new preoperative neurologic symptoms, which also increase the risk of stroke, cannot be influenced by surgical techniques, but these data argue that aggressive elective treatment of aortic aneurysms should reduce the incidence of adverse outcome after aortic operations. These results are not unexpected, ${ }^{2}$ but the consistent reports of better outcomes after elective rather than emergency aortic operations merit reiteration.

Compared with our earlier experience reported in 1994, only TCPT emerged as an additional risk factor for stroke. ${ }^{1}$ The idea that very long cerebral protection times may contribute to the incidence of stroke seems now, with an increasing number of patients, to be a consistent finding in our patient population. ${ }^{18}$ We still believe that stroke is predominantly embolic in origin, but the occurrence of mild diffuse cerebral injury (reflected clinically by higher rates of TND) with prolonged TCPTs may aggravate the effect of an embolic stroke in some cases, allowing prolonged TCPT to emerge as a risk factor if enough patients are studied. An embolus that blocks flow to a small defined area may lead to a clinically detectable stroke only if an additional prolonged period without adequate perfusion to surrounding tissues occurs. An effect of prolonged cerebral ischemic time on the incidence of stroke has previously been documented by Svensson and colleagues, ${ }^{19}$ who showed that HCA intervals longer than 40 minutes were associated with higher stroke rates. However, in our current subgroup of patients with TCPTs from 40 to 80 minutes, there was no indication that longer times within this range are associated with higher stroke rates, which is consistent with our earlier studies in smaller numbers of patients. We think that the higher stroke rates with extremely long TCPTs in the current group as a whole are largely a consequence of the association of long TCPTs with more extensive operations involving the aortic arch in patients with underlying atheromatous lesions predisposing to stroke.

The subgroup with TCPTs from 40 to 80 minutes affords us a unique opportunity to compare perfusion techniques with regard to effectiveness of cerebral protection, as reflected by the incidence of TND. In the subgroup analysis, as in the entire cohort, older age remains an important risk factor for TND. Another powerful predictor for TND is a cause involving either atherosclerosis or dissection. In addition, a remarkable protective effect of ACP is seen in this group of patients with prolonged operations, reinforcing the idea that providing an effective blood supply to the brain intraoperatively has a positive influence on cerebral recovery, even when the brain is protected by deep cooling.

\section{Conclusions}

Even though current brain protection techniques are not able to prevent embolic damage, this study demonstrates that ACP can reduce the more subtle global cerebral injury seen with inadequate cerebral protection during aortic operations reflected by a reduced incidence of TND when prolonged HCA is compared with ACP. Stroke rate is primarily a patient- and disease-related problem and seems independent of the use of different cerebral protection techniques, although its incidence is increased with very long TCPTs. The incidence of stroke is more likely to be effectively reduced by avoiding dislodgment of emboli, perhaps by modifying cannulation sites (eg, by using axillary cannulation). Unpublished data from our own experience seem to support this thesis. The positive effect of ACP on TND rate favors this technique when more extensive operations are planned. ACP allows aggressive treatment of more complex aortic pathologic conditions, although the safety of even ACP seems to be compromised when it exceeds 80 minutes.

A prospective randomized study with rigorous measurement of neurologic outcome would likely settle any lingering controversy about the best method for cerebral protection during aortic operations, but it is hard to imagine launching such a trial under current circumstances, when the results of admittedly imperfect clinical and experimental studies create a strong subjective bias favoring one approach over another under specific clinical circumstances. It seems clear that in operations likely to require more than a 40 minute interruption of normal circulation to the brain, $\mathrm{ACP}$ is the cerebral protection method of choice.

Received for publication July 5, 2000; revisions requested Oct 23, 2000; revisions received Nov 15, 2000; accepted for publication Nov 27, 2000.

Address for reprints: Christian Hagl, MD, Department of Cardiothoracic Surgery, Mount Sinai School of Medicine, One Gustave L. Levy Place, PO Box 1028, New York, NY 10029 (E-mail: chagl@ hotmail.com). 


\section{REFERENCES}

1. Ergin MA, Griepp EB, Lansman SL, Galla JD, Levy M, Griepp RB. Hypothermic circulatory arrest and other methods of cerebral protection during operations on the thoracic aorta. J Card Surg 1994;9:525-37.

2. Ergin MA, Uysal S, Reich DL, Apaydin A, Lansman SL, McCullough JN, et al. Temporary neurological dysfunction after deep hypothermic circulatory arrest: a clinical marker of longterm functional deficit. Ann Thorac Surg 1999;67:1887-90.

3. Reich DL, Uysal S, Sliwinski M, Ergin MA, Kahn RA, Konstadt $\mathrm{SN}$, et al. Neuropsychologic outcome after deep hypothermic circulatory arrest in adults. J Thorac Cardiovasc Surg 1999;117:156-63.

4. Ergin MA, Galla JD, Lansman SL, Quintana C, Bodian C, Griepp RB. Hypothermic circulatory arrest in operations on the thoracic aorta: determinants of operative mortality and neurologic outcome. J Thorac Cardiovasc Surg 1994;107:788-97.

5. Miller DC, Bachet J, David TE, Deeb M, Elefteriades JA, Lansman SL, et al. Discussion: Session 8-Aortic dissection. Ann Thorac Surg 1999;67:2014-9.

6. Ueda Y, Miki S, Kusuhara K, Okita Y, Tahata T, Yamanaka K. Surgical treatment of aneurysm or dissection involving the ascending aorta and aortic arch, utilizing circulatory arrest and retrograde cerebral perfusion. J Cardiovasc Surg 1990;31:553-8.

7. Boeckxstans CJ, Flameng WJ. Retrograde cerebral perfusion does not protect the brain in non-human primates. Ann Thorac Surg 1995;60:319-28.

8. Anttila V, Pokela M, Kiviluoma K, Makiranta M, Hirvonen J, Juvonen $\mathrm{T}$. Is maintained cranial hypothermia the only factor leading to improved outcome after RCP? An experimental study with a chronic porcine model. J Thorac Cardiovasc Surg 2000;119:1021-9.

9. Bavaria JE, Woo YJ, Hall RA, Carpenter JP, Gardner TJ. Retrograde cerebral and distal aortic perfusion during ascending and thoracoabdominal aortic operations. Ann Thorac Surg 1995;60:345-53.

10. Coselli JS. Retrograde cerebral perfusion in surgery for aortic arch aneurysms. In: Ennker J, Coselli JS, Hetzer R, editors. Cerebral protection in cerebrovascular and aortic surgery. Darmstadt, Germany: Steinkopf Verlag; 1997. p. 239-49.

11. Ehrlich MP, Fang WC, Grabenwoger M, Kocher A, Ankersmit J, Laufer G, et al. Impact of retrograde cerebral perfusion on aortic arch aneurysm repair. J Thoracic Cardiovasc Surg 1999;118:1026-32.

12. Griepp RB, Ergin MA, McCullough JN, Nguyen KH, Juvonen T, Chang N, et al. Use of hypothermic circulatory arrest for cerebral protection during aortic surgery. J Card Surg 1997;12:312-21.

13. Juvonen T, Weisz DJ, Wolfe D, Zhang N, Bodian CA, McCullough JN, et al. Can retrograde perfusion mitigate cerebral injury following particulate embolization? A study in a chronic porcine model. Ann Thorac Surg 1998;66:38-50.

14. Bachet J, Goudot B, Dreyfus G, Ayle NA, Aota M, Banfi C, et al. Antegrade selective cerebral perfusion with cold blood during aortic arch surgery. J Card Surg 1997;12:193-200.

15. Kazui T, Kimura N, Yamada O, et al. Surgical outcome of aortic arch aneurysm using selective antegrade perfusion. Ann Thorac Surg 1994;57:904-11.

16. Sakurada T, Kazui T, Tanaka H, et al. Comparative experimental study of cerebral protection during aortic arch reconstruction. Ann Thorac Surg 1996;61:1348-54.

17. Dossche KM, Schepens MAAM, Moshuis WJ, Muysoms FE, Langemeijer JJ, Vermeulen FEE. Antegrade selective cerebral perfusion in operations on the proximal thoracic aorta. Ann Thorac Surg 1999;67:1904-10.

18. Ehrlich MP, Ergin MA, McCullough JN, et al. Predictors of adverse outcome and transient neurological dysfunction following ascending aorta/aortic arch replacement. Ann Thorac Surg 2000;69:1755-63.

19. Svensson LG, Crawford ES, Hess KR, Coselli JS, Raskin S, Shenaq SA, et al. Deep hypothermia with circulatory arrest: determinants of stroke and early mortality in 656 patients. J Thorac Cardiovasc Surg 1993;106:19-31.

\section{Discussion}

Dr R. Scott Mitchell (Woodside, Calif). Drs Hagl and Ergin and the Mount Sinai group are to be congratulated for yet another contribution toward our understanding of mechanisms of neurologic injury during HCA. Their clinical and laboratory research could almost be viewed as the Mount Sinai quest for the holy grail.

In brief, these advances include the following:

1. Use of alternative cannulation sites to minimize retrograde propagation of aortic and iliac artery atheroemboli

2. Prolonged core cooling to core temperatures of $10^{\circ} \mathrm{C}$ to $13^{\circ} \mathrm{C}$ to assure homogeneous cerebral hypothermia

3 . Increasing dependence on antegrade cerebral perfusion for neurologic protection during prolonged procedures

Operative mortality was $10 \%$ and was profoundly affected by neurologic injury, which increased hospital mortality by $400 \%$. Interestingly, for stroke, only increasing age correlated with increased risk. However, for the somewhat more subtle TND, which occurred in $30 \%$ of patients, increasing age, cause of atherosclerosis or dissection, and RCP adversely affected results. Although this is not a randomized trial, and indeed the operative management changed substantially over the time period of this study, I do believe these results constitute the best available technique.

I do have 3 questions. First, with the substantial amount of data coming from Japan, how do you reconcile your findings with many of the reports, like that from Osaka, that have demonstrated no adverse effect and in fact have demonstrated a good effect of RCP for prolonged circulatory arrest times?

Dr Hagl. Thank you very much, Dr Mitchell, for your kind remarks. We think that the positive effects which were shown from groups using RCP are due to better cooling. The Mount Sinai group cools more aggressively (ie, to $10^{\circ} \mathrm{C}$ or $12^{\circ} \mathrm{C}$ ) than most other groups. Surgeons who cool to just $18^{\circ} \mathrm{C}$ and then perfuse the brain in a retrograde manner may have more complete cooling with RCP than otherwise. It may also be theoretically possible to flush out some emboli by using the RCP technique. Nevertheless, we have not seen any beneficial effects in our patients with that method.

Dr Mitchell. Second, did you attempt to analyze any sort of a subcategory for those patients in whom you did these more proximal alternative cannulations on axillary, subclavian, innominate arteries? 
Dr Hagl. This was not part of the present study. We have, however, analyzed our results for axillary cannulation in a single surgeon's experience, and it seems, comparing the femoral artery cannulation with the axillary cannulation, that axillary cannulation has a much better outcome and a much lower stroke rate. Therefore, we have begun using axillary cannulation almost exclusively in the last 2 years and try to avoid femoral cannulation if possible.

Dr Mitchell. Because there still appears to be some substantial neurologic injury with prolonged periods of HCA, do you think we should perhaps return to selective antegrade continuous perfusion for these difficult and prolonged arch cases?

Dr Hagl. I think what we showed here is that it is definitely useful to do ACP in more extensive operations with prolonged periods of HCA. To offer the brain some cold oxygenated blood seems to protect the cerebrum from the more subtle neurologic injury, what we term TND. We still think that TND is probably caused by imperfect brain protection. I would like to emphasize that I think it is very important to do ACP with cold, rather than warm, blood.

Dr Dev Manhas (Seattle, Wash). I enjoyed the article very much. I have a question about ACP. Are you perfusing both the innominate and the left common carotid arteries? What is your perfusion rate and pressure monitoring when you do that? Are you checking the carotid arteries preoperatively by using Doppler ultrasonography?

Dr Hagl. What we do is to create an island of native arch and perfuse the head vessels through an attached graft without cannulation of the native vessel. The perfusion rate is approximately 700 to $1200 \mathrm{~mL} / \mathrm{min}$, but we believe it is more important to measure the pressure in the radial artery. We rely more on pressure measurement than on the flow rate.

Concerning your second question, we do not routinely carry out preoperative evaluation of carotid arteries unless specific indications like a bruit or a neurologic history are present.

\section{Bound volumes available to subscribers}

Bound volumes of The Journal of Thoracic and Cardiovascular Surgery are available to subscribers (only) for the 2001 issues from the Publisher, at a cost of $\$ 134.00$ for domestic, $\$ 165.85$ for Canadian, and $\$ 155.00$ for international subscribers for Vol 121 (January-June) and Vol 122 (July-December). Shipping charges are included. Each bound volume contains a subject and author index and all advertising is removed. Copies are shipped within 60 days after publication of the last issue of the volume. The binding is durable buckram with the Journal name, volume number, and year stamped in gold on the spine. Payment must accompany all orders. Contact Mosby, Subscription Customer Service, 6277 Sea Harbor Dr, Orlando, FL 32887,USA; phone 800-654-2452 or 407-345-4000.

Subscriptions must be in force to qualify. Bound volumes are not available in place of a regular Journal subscription. 